\title{
Patterns of Dual-Specific Phosphatase 4 mRNA Expression Before and after Neoadjuvant Chemotherapy in Breast Cancer
}

\author{
Prihantono Prihantono ${ }^{1 *}$, Andi Nilawati Usman ${ }^{2}$, Christian Binekada ${ }^{3}$, \\ Mochammad Hatta ${ }^{4}$, Andi Asadul Islam ${ }^{1}$
}

\begin{abstract}
Objective: Evaluation of the neoadjuvant chemotherapy response can be performed by comparing the breast cancer burden and pathobiology before and after treatment. This study was aimed to investigate the pattern of dualspecific phosphatase 4 (DUSP4) mRNA expression in breast cancer cells before and after neoadjuvant chemotherapy. Methods: This was a longitudinal study. Twenty samples of matched breast cancer tissue taken from biopsy before and after chemotherapy were subjected to qRT-PCR to detect DUSP4 mRNA expression. Results: The mean value of DUSP 4 mRNA expression in prechemotherapy breast cancer patients was $9.906 \pm 0.333$ and that in breast cancer patients postchemotherapy was $10.016 \pm 1.062$. In the responsive group, the rate of DUSP 4 mRNA expression increased by 0.476 after chemotherapy. In the nonresponsive group, the proportion of DUSP $4 \mathrm{mRNA}$ expression likely decreased by 1.012 . Statistical analysis found no significant correlation between DUSP 4 mRNA expression prechemotherapy and the clinical chemotherapeutic response with $p$-value $=0.994(p \geq 0.05)$. A significant correlation was found between the postchemotherapy DUSP4 mRNA expression and the clinical chemotherapeutic response with $\mathrm{p}$-value $=0.003(\mathrm{p}<0.5)$. Conclusion: No significant difference was found in the mRNA expression of DUSP4 in pre- and post-neoadjuvant chemotherapy specimens. High DUSP4 expression postchemotherapy shows a substantial correlation with the chemotherapeutic response.
\end{abstract}

Keywords: DUSP4- mRNA- qRT-PCR- Chemotherapy response

Asian Pac J Cancer Prev, 20 (4), 1051-1055

\section{Introduction}

Breast cancer is the most common cancer and the second leading cause of cancer death in women worldwide, including Indonesia (Bray et al., 2013; Youlden et al., 2014). Advances in systemic therapy, such as chemotherapy, hormonal therapy, and targeting treatment, have improved the patient disease-free survival and overall survival, but some cancers are resistant to systemic therapy (Martin et al., 2014; Miller et al., 2016). Cancer patients with the same stage, grade, and histogenesis can have different treatment responses to various chemotherapy agents (Luqmani, 2005; Rouzier et al., 2005; Györffy et al., 2006). Some theories have proposed the mechanisms of therapeutic resistance. Biomarker and gene-specificity for chemotherapeutic resistance are challenges to be addressed (Holohan et al., 2013).

Neoadjuvant chemotherapy offers an estimation of the treatment response (Cortazar et al., 2014; Zardavas and Piccart, 2015). Chemotherapy induces upregulation or downregulation of most genes (Klintman et al., 2016). Residual disease after neoadjuvant chemotherapy may predict the prognosis and gene expression in residual disease, suggesting a biologic role in chemoresistant disease (Balko et al., 2012; Klintman et al., 2016) (Penault-Llorca and Radosevic-Robin, 2016).

Dual-specificity phosphatase 4 (DUSP4) is a protein responsible for dephosphorylating threonine/serine and tyrosine residues on their substrates (Boulding et al., 2016). DUSP4 selectively dephosphorylates signaling Mitogen-activated protein kinase's (MAPKs), implicating them in signal transduction. Studies have found that DUSP4 is upregulated in malignant tissues, including breast cancer (Boulding et al., 2016).

Mazumdar et al., (2016) identified the low expression of the DUSP4 protein in ER-negative breast cancers. Overexpression of DUSP 4 protein causes dephosphorylation of growth-promoting signaling proteins, hence inhibiting the growth and invasiveness of ER-negative breast cancer cells.

DUSP4 is significantly enriched in response to

${ }^{1}$ Department of Surgery, ${ }^{4}$ Biology Molecular and Immunology Laboratory, Faculty of Medicine, ${ }^{2}$ Department of Statistics, Faculty of Health Community, Hasanuddin University, Makassar, ${ }^{3}$ Department of Surgery, Faculty of Medicine, Haluoleo University, Kendari, Indonesia.*For Correspondence: prihantono.md@gmail.com 
chemotherapy, and low levels of DUSP4 in residual disease are associated with an impaired prognosis (Klintman et al., 2016). The loss of DUSP4 activates the MAPK pathway, promoting a stem cell-like phenotype and decreasing the clinical response to neoadjuvant therapy in breast cancer (Balko et al., 2012; Balko et al., 2013). Some other studies also found that DUSP4 expression is associated with resistance to cytotoxic chemotherapies such as doxorubicin and cisplatin chemoresistance (Liu et al., 2013; Boulding et al., 2016).

The objective of this study was to determine the pattern of DUSP 4 mRNA expression in locally advanced breast cancer patients pre- and post-neoadjuvant chemotherapy using anthracycline-based chemotherapy and the relationship with the clinical chemotherapeutic response.

\section{Materials and Methods}

\section{Samples}

This was an observational study. The samples were obtained from Wahidin Sudirohusodo Hospital Makassar, a top referral hospital in the east of Indonesia, from February to June 2016. Female patients with locally advanced breast cancer, invasive ductal carcinoma type, receiving neoadjuvant chemotherapy with a cyclophosphamideadriamycin-5-FU regimen, were included in the study. The DUSP4 mRNA expression was detected using quantitative real-time polymerase chain reaction (qRT-PCR) from breast cancer tissue taken from biopsy and surgery.

\section{Nucleic Acid Extraction}

Samples of breast cancer tissue were subjected to nucleic acid extraction using the Boom method (diatom guanidinium isothiocyanate (GuSCN) method). Breast cancer tissue as much as $100 \mu \mathrm{g} / \mathrm{ul}$ was added to $900 \mathrm{~mL}$ "L6" solution containing $120 \mathrm{~g} \mathrm{GuSCN}$, $100 \mathrm{ml} 0.1 \mathrm{mM}$ Tris-HCl, pH 6.4, $22 \mathrm{ml} 0.2 \mathrm{mM}$ ethylenediaminetetraacetate (EDTA), $\mathrm{pH} 8.0$, and $2.6 \mathrm{~g}$ Triton X-100 (final concentrations of $50 \mathrm{mM}$ Tris- $\mathrm{HCl}$, $5 \mathrm{M} \mathrm{GuSCN}, 20 \mathrm{mM}$ EDTA, and 0.1\% Triton X-100). Next, $20 \mathrm{ml}$ diatom suspension was added consisting of $50 \mathrm{ml} \mathrm{H_{2 }} \mathrm{O}$ and $500 \mathrm{~mL} \mathrm{32 \%} \mathrm{(w/v)} \mathrm{Diatoms.} \mathrm{This} \mathrm{diatom}$ suspension, which could bind $10 \mu \mathrm{g}$ DNA tissue, was vortexed and centrifuged in a 1.5-ml Eppendorf tube at 13,000 rpm for 15 seconds. The supernatant was removed, and the sediment was washed with $1 \mathrm{ml}$ "L2" solution (120 g GuSCN in $100 \mathrm{ml} \mathrm{0.1} \mathrm{M} \mathrm{Tris-HCl,} \mathrm{pH} \mathrm{6.4).} \mathrm{Next,}$ the sample was vortexed and then centrifuged at 13,000 rpm for 15 seconds. Next, the sediment was washed twice with "L2" solution and twice with $1 \mathrm{ml} 70 \%$ ethanol and $1 \mathrm{ml}$ acetone. The sample was then heated in a water bath at a temperature of $56^{\circ} \mathrm{C}$ for 10 minutes, followed by the addition of $60 \mathrm{~mL}$ "TE" solution (1 mM EDTA in $10 \mathrm{mM}$ Tris-HCl, pH 8.0), vortexing and centrifugation at 13,000 rpm for 2 minutes. The sample was then incubated in an oven at $56^{\circ} \mathrm{C}$ for 10 minutes, followed by vortexing and centrifugation at $13,000 \mathrm{rpm}$ for 30 seconds and collection of the supernatant. This supernatant was the result of nucleotide extraction and was stored at $-80^{\circ} \mathrm{C}$ before PCR analysis (Boom et al., 1990; Prihantono et al., 2017).
Expression of mRNA DUSP4 Genes by Real-Time PCR

The detection of DUSP 4 mRNA expression was performed according to real-time PCR as described by Liu et al. (Liu et al., 2013). The specific primers for DUSP 4 mRNA were as follows: forward, 5'- CCCACAGAGCAGTATTAGGCTGAAG-3'; reverse, 5'-CAGCGTGGATGAGCAACTGAA-3'. The primers for the reference gene ( $\beta$-actin gene) were as follows: forward, 5'-GGAGATTACTGCC- CTGGCTCCTA-3'; reverse, 5'- GACTCATCGTACTCCTGCTTGCTG-3'. Each sample required $1 \mu \mathrm{g}$ of the template. Reverse transcription was performed using the RT reagent Kit with gDNA eraser. cDNA was synthesized using the cDNA Synthesis kit (Takara) following the instructions provided by the manufacturers. qRT-PCR was performed using an ABI7500 Sequence Detection System (PE Applied Biosystems) in the presence of SYBR-green I. Briefly, a 50- $\mu$ l reaction mix containing $25 \mu$ Premix ExTaq, Takara), $1 \mu$ ROX reference Dye II ( Takara), $1 \mu$ PCR forward primer $(10 \mu \mathrm{M}), 1 \mu \mathrm{l}$ PCR reverse primer $(10 \mu \mathrm{M})$, $4 \mu \mathrm{l}$ cDNA and $18 \mu \mathrm{ldH}_{2} \mathrm{O}$ was premixed before reaction in 96 -well plates. The reaction protocol was as follows: $95^{\circ} \mathrm{C}$ for $30 \mathrm{~s}, 40$ cycles of $95^{\circ} \mathrm{C}$ for $5 \mathrm{~s}$ and $60^{\circ} \mathrm{C}$ for 34 $\mathrm{s}$, followed by $95^{\circ} \mathrm{C}$ for 15 seconds, $60{ }^{\circ} \mathrm{C}$ for 1 minute and $95^{\circ} \mathrm{C}$ for 15 seconds. The relative gene expression profiles were determined by normalizing to the reference gene ( $\beta$-actin) using the 2_ $\Delta \mathrm{Ct}$ method. Each sample for this study was tested in triplicate (Liu et al., 2013).

\section{Chemotherapeutic Response Criteria}

The response to neoadjuvant chemotherapy was classified according to RECIST criteria. The nonresponsive group displayed stable disease or progressive disease according to RECIST criteria if there is a reduction of the tumor size less than $30 \%$, no change, an increase in the tumor size, or a new tumor. The responsive groups displayed a complete or partial response if there is a reduction of the tumor size $>30 \%$, no evidence of a tumor clinically or pathologically, or no further tumor found.

\section{Ethical Clearance}

This study has been approved by the Ethical Commission of Health Study, Medical Faculty, Hasanuddin University, with the registry number 799/H4.8.4.5.31/ PP36-KOMETIK/2016 (Register: UH15060492).

\section{Results}

\section{Characteristics}

The twenty enrolled female patients with invasive breast carcinoma diagnosed and treated at Wahidin Sudirohusodo General Hospital met the inclusion criteria of the study. Their ages ranged from 28 to 64 years, with a mean age of 50.3 years. All twenty cases were invasive ductal carcinoma. The obtained histopathologic grading was a low grade in 1 case $(5 \%)$, moderate grade in 15 cases $(75 \%)$ and high grade in 4 cases $(20 \%)$. The number of patients responsive to neoadjuvant chemotherapy was $15 / 20(75 \%)$, and the number of nonresponsive patients was $5 / 20(25 \%)$. No correlation was found between DUSP 4 mRNA expression and clinical data, including 
Table 1. Characteristics of Samples

\begin{tabular}{lcc}
\hline Characteristic & $\mathrm{n}(\%)$ & $\mathrm{p}^{*}$ \\
\hline Age & & 0.617 \\
$\quad \leq 50$ years & $11(55.0 \%)$ & \\
$>50$ years & $9(45.0 \%)$ & \\
Grade & & 0.225 \\
$\quad$ Low Grade & $1(5.0 \%)$ & \\
$\quad$ Moderate Grade & $15(75.0 \%)$ & \\
High Grade & $4(20.0 \%)$ & \\
Immunohistochemistry & & 0.56 \\
ER & $5(25.0 \%)$ & \\
PR & $6(30.0 \%)$ & \\
HER2 & $13(65.0 \%)$ & \\
Ki-67 & $11(55.0 \%)$ & \\
Clinical response & & 0.959 \\
Luminal A & $3(15.0 \%)$ & \\
Luminal B & $6(30.0 \%)$ & \\
HER2 & $7(35.0 \%)$ & \\
Triple Negative & $4(20.0 \%)$ & \\
Clinical response & $15(75.0 \%)$ & \\
Responsive & $5(25.0 \%)$ & \\
Nonresponsive &
\end{tabular}

*p, chi-squared test for the clinical chemotherapy response

age and grade. The characteristics of the samples are presented in Table 1, and the amplification curve of DUSP4 prechemotherapy and postchemotherapy is shown in Figure 1.

Comparison of the mRNA DUSP 4 expression pre- and postchemotherapy is shown in Table 2 . The mean value of DUSP 4 mRNA expression in breast cancer patients prechemotherapy who were responsive to chemotherapy was $9.902 \pm 0.336$, whereas that of nonresponsive patients was $9.917 \pm 0.378$. The mean value of DUSP4 mRNA expression postchemotherapy in those sensitive to chemotherapy was $10.378 \pm 0.785$, whereas that of nonresponsive patients was $8.905 \pm 1.082$. In the sensitive group, DUSP 4 mRNA expression increased by 0.476 . In the nonresponsive group, the DUSP 4 mRNA expression

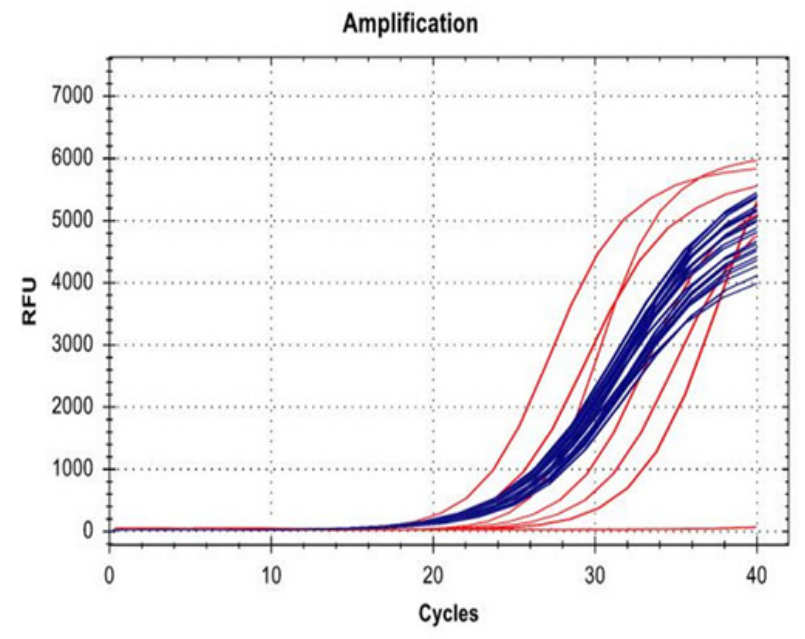

a)

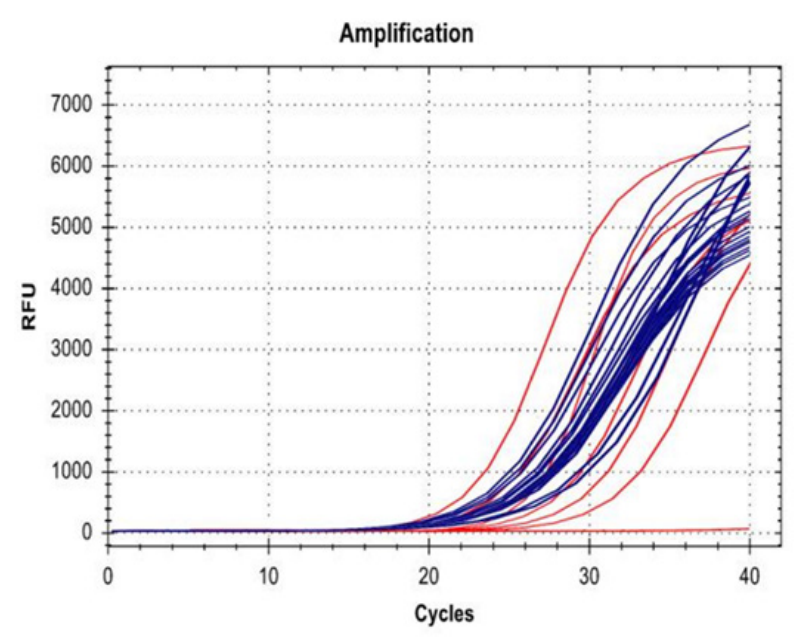

b)

Figure 1. Amplification Curve of DUSP4: a) Prechemotherapy; b) Postchemotherapy

decreased by 1.012. No significant difference was found in the mean DUSP 4 mRNA expression value between the prechemotherapy group and the group with clinical response to chemotherapy ( $\mathrm{p}$-value $=0.939 ; \mathrm{p} \geq 0.05$ ). A significant mean difference was found between DUSP4 mRNA expression postchemotherapy and the clinical

Table 2. Comparison of the mRNA DUSP4 Expression Pre- and Postchemotherapy with the Clinical Response

\begin{tabular}{lccc}
\hline mRNA Expression & Responsive $(\mathrm{n}=20)$ & Non Responsive $(\mathrm{n}=7)$ & Mean difference $\mathrm{p}$-value \\
\hline DUSP4 (Prechemotherapy) & $9.902 \pm 0.336$ & $9.917 \pm 0.378$ & $-0.015^{*}$ \\
DUSP4 (Postchemotherapy) & $10.378 \pm 0.785$ & $8.905 \pm 1.082$ & $1.472^{* *}$ \\
Mean difference & -0.476 & 1.012 & \\
\hline
\end{tabular}

Source: Primary Data, *Independent Samples T-test, **Mann-Whitney U test

Table 3. Correlation of the mRNA DUSP4 Expression and the Clinical Chemotherapeutic Response

\begin{tabular}{lccc}
\hline & $\begin{array}{c}\text { mRNA Expression } \\
(\text { Mean } \pm \text { SD) }\end{array}$ & $\begin{array}{c}\text { Correlation with the } \\
\text { Chemotherapy response }\end{array}$ & $\mathrm{p}$ \\
\hline DUSP4 mRNA (Prechemotherapy) & $9.906 \pm 0.333$ & -0.002 & $0.994^{*}$ \\
DUSP4 mRNA (Postchemotherapy) & $10.016 \pm 1.062$ & 0.494 & $0.027^{* *}$ \\
Rate of DUSP4 mRNA Expression & $1.329 \pm 1.283$ & 0.24 & $0.307^{* *}$ \\
\hline
\end{tabular}

Source: Primary Data, * Pearson, ${ }^{* *}$ Spearman 
response to chemotherapy $(\mathrm{p}$-value $=0.003 ; \mathrm{p} \geq 0.05)$.

The relationship between the DUSP 4 mRNA expression and the clinical response is demonstrated in Table 3. No significant correlation was found between the mRNA expression of DUSP4 prechemotherapy with the clinical response $(p=0.994 ; p>0.05)$. A definite correlation was found between DUSP 4 mRNA expression postchemotherapy and the clinical response $(r=0.494)$; this association was significant with $\mathrm{p}=0.027(\mathrm{p}<0.05)$. A definite correlation was found between the rate of DUSP 4 mRNA expression and the clinical response with a value of $r=0.240$; this association was insignificant with $\mathrm{p}=0.307(\mathrm{p}>0.05)$.

\section{Discussion}

Breast cancer chemo-resistance influenced by several factors including drug inactivation, changes in drug targets, overexpression of ABC transporters, apoptotic dysregulation, epigenetic regulation, epithelial to mesenchymal transition, and cancer stem cells (Housman et al., 2015).

DUSP4 expression has been found in various human cancers (Kidger and Keyse, 2016). Over-expression of DUSP4 is frequently observed in breast cancer and may play an essential role in cancer development and progression (Wang et al., 2003). DUSP4 is commonly upregulated in breast malignancy and may play a crucial role in cancer development and progression. DUSP 4 may be a marker of adverse prognosis, especially in patients with early breast cancer (Kim et al., 2015).

Decreased expression of DUSP4, a negative regulator of extracellular signal-regulated kinases (ERK), is related to high RAS-ERK activation and has been recently identified as a mediator of resistance to neoadjuvant chemotherapy in triple-negative breast cancer, promoting to a shorter recurrence-free survival (Balko et al., 2012; Rottenberg and Jonkers, 2012). DUSP 4 expression was also found to be responsible for the resistance to etoposide and mitoxantrone chemotherapy in breast cancer (Györffy et al., 2006).

We found that increased DUSP 4 mRNA expression showed a better chemotherapy response than decreased DUSP 4 mRNA expression, but the difference was not statistically significant. DUSP 4 mRNA expression postchemotherapy was associated with chemotherapy response.

In our previous study on the expression of DUSP4 using immunohistochemistry, DUSP4 expression was found in 33\% (21/63) of breast cancer samples. Analysis of DUSP4 expression with a chemotherapy response found no significant correlation, with $\mathrm{p}=0.073(>0.05)$. However, stratification of DUSP 4 expression based on the intrinsic subtype found that the Luminal B p-value $=0.02$ $(<0.05)$, the Luminal A p-value $=0.24(>0.05)$, and the Her2 $\mathrm{p}$-value $=0.608(>0.05)$; the triple-negative subtype could not be analyzed because of the small number of samples. Furthermore, DUSP 4 expression was correlated with the anthracycline-based chemotherapy response in the luminal B subtype (Prihantono et al., 2017).

Balko et al., (2012) found that low DUSP4 expression was associated with basal-like breast cancer, high tumor proliferation after chemotherapy, and a decrease in the clinical chemotherapeutic response and achieved poorer pathologic complete remission rates and shorter recurrence-free survival periods than those in patients with high levels of DUSP 4 expression. By contrast, DUSP 4 overexpression was associated with increased apoptosis induced by chemotherapy (Balko et al., 2012).

Baglia et al., (2014), in his study, found that low DUSP 4 expression was associated with increased recurrence and mortality in triple-negative breast cancer patients. Baglia concluded that low DUSP4 expression is a predictor of recurrence and death in triple-negative breast cancer patients.

Liu et al., (2013) demonstrated that DUSP4 expression affects the breast cancer cell response to chemotherapy. High DUSP 4 expression requires higher doses of doxorubicin, whereas cells with low DUSP4 expression need lower doses of doxorubicin. Doxorubicin chemotherapy in breast cancer cells with high DUSP4 expression can lead to acquired chemoresistance by converting epithelial cells into mesenchymal (EMT) cells (epithelial-to-mesenchymal transition). With these EMT changes, cancer cells become more actively proliferating, invasion, migration, and apoptosis are reduced, and the cells become less sensitive to chemotherapy.

Hae Hyun Jung (2016), suggest that the loss of DUSP 4, a potential biomarker of treatment-resistant TNBC, is associated with ets- 1 overexpression via the PI3K and MAPK pathways. Statin, a small inhibitor of HMG-CoAR, is a likely therapeutic candidate for treatment-resistant TNBC because it can reverse ets-1 overexpression by restoring DUSP 4 expression.

This study found DUSP 4 mRNA expression postchemotherapy was associated with chemotherapy response. This finding is in line with the article of Rottenberg and Jonkers (2012), Cells with low DUSP4 expression show a high $\mathrm{Ki}-67$ score, which is associated with a poor long-term outcome after neoadjuvant chemotherapy. Hence, the residual cells that show low DUSP 4 expression are not quiescent, drug-tolerant cells. Instead, they appear to be genuinely drug-refractory and proliferate regardless of drug treatment. Residual cancer cells may still have another backup: entering a quiescence programme and lying low until the drug is eliminated (Rottenberg and Jonkers, 2012).

In conclusion, no significant difference was found in the DUSP 4 mRNA expression of pre- and post-neoadjuvant chemotherapy specimens. Increased DUSP 4 mRNA expression shows the tendency of better chemotherapy response, but it is not statistically significant. These results do not suggest that DUSP4 mRNA expression plays a role in conferring neoadjuvant chemotherapy resistance. DUSP4 expression postchemotherapy has a substantial correlation with the chemotherapy response. The findings warrant further research to observe the disease-free survival and overall survival with a larger sample size.

\section{Grant Support}

This study was supported by funds from the Ministry of Health of the Republic of Indonesia through a research 
grant for novice researchers entitled "RISBINIPTEKDOK 2016".

\section{Conflicts of Interest}

We have no conflicts of interest.

\section{Acknowledgments}

We extend our gratitude to all the breast cancer patients who participated in this study.

\section{References}

Baglia ML, Cai Q, Zheng Y, et al (2014). Dual specificity phosphatase 4 gene expression in association with triple-negative breast cancer outcome. Breast Cancer Res Treat, 148, 211-20.

Balko JM, Cook RS, Vaught DB, et al (2012). Profiling of residual breast cancers after neoadjuvant chemotherapy identifies DUSP 4 deficiency as a mechanism of drug resistance. Nat Med, 18, 1052.

Balko JM, Schwarz LJ, Bhola NE, et al (2013). Activation of MAPK pathways due to DUSP 4 loss promotes cancer stem cell-like phenotypes in basal-like breast cancer. Cancer Res, 73, 6346-58.

Boom R, Sol C, Salimans M, et al (1990). Rapid and simple method for purification of nucleic acids. J Clin Microbiol, 28, 495-503.

Boulding T, Wu F, McCuaig R, et al (2016). Differential roles for DUSP family members in epithelial-to-mesenchymal transition and cancer stem cell regulation in breast cancer. PLoS One, 11, e0148065.

Bray F, Ren JS, Masuyer E, et al (2013). Global estimates of cancer prevalence for 27 sites in the adult population in 2008 . Int J Cancer, 132, 1133-45.

Cortazar P, Zhang L, Untch M, et al (2014). Pathological complete response and long-term clinical benefit in breast cancer: the CTNeoBC pooled analysis. Lancet, 384, 164-72.

Housman G, Byler S, Heerboth S, et al (2014) Drug resistance in cancer: an overview. Cancers, 6, 1769-92.

Györffy B, Surowiak P, Kiesslich O, et al (2006). Gene expression profiling of 30 cancer cell lines predicts resistance towards 11 anticancer drugs at clinically achieved concentrations. Int J Cancer, 118, 1699-712.

Holohan C, Van Schaeybroeck S, Longley DB, et al (2013). Cancer drug resistance: an evolving paradigm. Nat Rev, Cancer, 13, 714.

Jung HH, Lee SH, Kim JY, et al (2016). Statins affect ETS1-overexpressing triple-negative breast cancer cells by restoring DUSP4 deficiency. Sci Rep, 6, 33035.

Kidger AM, Keyse SM (2016). Dual-specificity Map Kinase (MAPK) Phosphatases (MKPs) and their involvement in cancer. In 'Protein Tyrosine Phosphatases in Cancer'. Springer, New York, pp 201-31.

Kim H, Jang SM, Ahn H, et al (2015). Clinicopathological significance of dual-specificity protein phosphatase 4 expressions in invasive ductal carcinoma of the breast. $J$ Breast Cancer, 18, 1-7.

Klintman M, Buus R, Cheang MCU, et al (2016). Changes in expression of genes representing key biologic processes after neoadjuvant chemotherapy in breast cancer, and prognostic implications in residual disease. Clin Cancer Res, 22, 2405-16.

Liu Y, Du F, Chen W, et al (2013). Knockdown of dual specificity phosphatase 4 enhances the chemosensitivity of MCF-7 and MCF-7/ADR breast cancer cells to doxorubicin. Exp Cell

$$
\text { Res, 319, 3140-9. }
$$

Luqmani YA (2005). Mechanisms of drug resistance in cancer chemotherapy. Med Princ Pract, 14, 35-48.

Martin HL, Smith L, Tomlinson DC (2014). Multidrug-resistant breast cancer: current perspectives. Breast Cancer, 6, 1 .

Mazumdar A, Poage GM, Shepherd J, et al (2016). Analysis of phosphatases in ER-negative breast cancers identifies DUSP 4 as a critical regulator of growth and invasion. Breast Cancer Res Treat, 158, 441-54.

Miller KD, Siegel RL, Lin CC, et al (2016). Cancer treatment and survivorship statistics. CA Cancer J Clin, 66, 271-89.

Penault-Llorca F, Radosevic-Robin N (2016). Biomarkers of residual disease after neoadjuvant therapy for breast cancer. Nature Rev Clin Oncol, 13, 487.

Prihantono P, Hatta M, Binekada C, et al (2017). Ki-67 Expression by Immunohistochemistry and quantitative real-time polymerase chain reaction as predictor of clinical response to neoadjuvant chemotherapy in locally advanced breast cancer. J Oncol, 2017, 1-8.

Prihantono P, Hatta M, Sampepajung D, et al (2017). Association of Dual Specific Phosphatase 4 (DUSP4) expression and anthracycline-based neoadjuvant chemotherapy response in breast cancer. IJSBAR, 31, 125-33.

Rottenberg S, Jonkers J (2012). MEK inhibition as a strategy for targeting residual breast cancer cells with low DUSP 4 expression. Breast Cancer Res, 14, 324.

Rouzier R, Perou CM, Symmans WF, et al (2005). Breast cancer molecular subtypes respond differently to preoperative chemotherapy. Clin Cancer Res, 11, 5678-85.

Wang H-y, Cheng Z, Malbon CC (2003). Overexpression of mitogen-activated protein kinase phosphatases MKP1, MKP2 in human breast cancer. Cancer Lett, 191, 229-37.

Youlden DR, Cramb SM, Yip CH, et al (2014). Incidence and mortality of female breast cancer in the Asia-Pacific region. Cancer Bio Med, 11, 101.

Zardavas D, Piccart M (2015). Neoadjuvant therapy for breast cancer. Annu Rev Med, 66, 31-48.

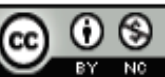

This work is licensed under a Creative Commons AttributionNon Commercial 4.0 International License. 